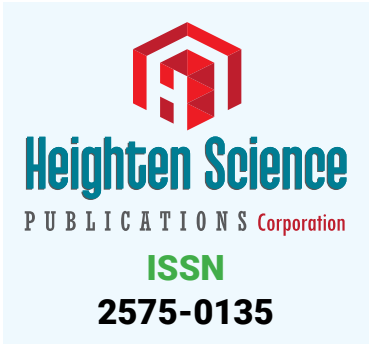

*Address for Correspondence: Prof. Cinzia Forni, Department of Biology, University of Rome Tor Vergata Via della Ricerca Scientifica, 00133 Rome (Italy), Email: forni@uniroma2.it

Submitted: 29 September 2017

Approved: 09 October 2017

Published: 11 October 2017

Copyright: @ 2017 Rossi M, et al. This is an open access article distributed under the Creative Commons Attribution License, which permits unrestricted use, distribution, and reproduction in any medium, provided the original work is properly cited.

Keywords: Chlorophyll; xanthophylls; Dye; DSSC
Research Article

\section{Chlorophylls and xanthophylls of crop plants as dyes for Dye- Sensitized Solar Cells (DSSC)}

\author{
Rossi $\mathbf{M}^{1}$, Matteocci $\mathrm{F}^{2}$, Di Carlo $\mathrm{A}^{2}$ and Forni $\mathrm{C}^{1 *}$ \\ 'Department of Biology, University of Rome Tor Vergata, Via della Ricerca Scientifica, 00133 \\ Roma, Italy \\ ${ }^{2} \mathrm{CHOSE}-$ Centre for Hybrid and Organic Solar Energy-University of Rome Tor Vergata, via del \\ Politecnico 1, 00133 Roma, Italy
}

\section{Abstract}

Natural dyes have become a viable alternative to expensive and rare organic sensitizers because of their low cost, easy attainability, abundance of supply of raw materials and environmental friendliness. Chlorophyll, the most abundant pigment, can be extracted from plant leaves with simple and inexpensive methods, but it's difficult to use as a Dye-Sensitized Solar Cells (DSSC) sensitizer due to the absence of $\mathrm{OH}$ and $\mathrm{COOH}$ groups. The opposite is true for xanthophylls, a particular class of carotenoids that contain free hydroxyl groups and thus may be considered as potential DSSC sensitizers. In this work we describe a new and inexpensive method of chlorophyll extraction from leaves based on the use of a basic solvent that provides the creation of $\mathrm{COOH}$ groups, allowing chlorophyll binding on the $\mathrm{TiO}_{2}$ layer. This modified chlorophyll dye showed a higher DSSC efficiency level (0.72\%) compared to xanthophylls, which had lower efficiency.

\section{Introduction}

Dye-Sensitized Solar Cells (DSSC) were inspired by the characteristic electron transfer mechanism of photosynthesis. This technology, created by Grätzel [1], is based on the use of four different components, which, acting simultaneously, generate a regenerative electrochemical process based on a mechanism of electronic injection [2]. The working voltage produced by the cells is the difference between the chemical potential of the electron acceptor (Fermi level) and the redox potential of the electron donor. The electrical circuit is composed by: a dye as a light harvester, a $\mathrm{TiO}_{2}$ layer as an electron acceptor, a iodide/triiodide $\left(\mathrm{I}^{-} / \mathrm{I}_{3}^{-}\right)$electrolyte as an electron donor and a platinum (Pt) counter-electrode on the cathode. The chemical reactions of the injection mechanism is based on the following three phases: light absorption, electron injection, and regeneration.

DSSC are composed of the following four components: 1) semi-conductor, 2) electrolyte, 3) counter-electrode, 4) dyes [3]. The semi-conductor must have two characteristics in order to be used, i.e. a high dye chemisorption capacity and a high dielectric constant which enables the shielding of the injected electron, avoiding the recombination with the oxidized dye. The most used semiconductor, based on its performances and price, is titanium dioxide $\left(\mathrm{TiO}_{2}\right.$ or titania) in anatase form. $\mathrm{TiO}_{2}$ shows a high dielectric constant that prevents electron recombination with the dye, and a high refractive index that allows a homogeneous distribution of light within the nanoporous layer. 
The electrolyte task provides a new electron to the dye with the aim of restarting the injection cycle of the electron. Cell voltage and current intensity, two parameters which produce the efficiency of the Grätzel cell, are electrolyte-dependent. Usually electrolytes contain $\mathrm{I}^{-} / \mathrm{I}_{3}-$ redox ions, but there are also bromine electrolytes $\left(\mathrm{Br}^{-} / \mathrm{Br}_{2}\right)$. The reaction that occurs in the electrolyte is: $3 \mathrm{I}^{-} \rightarrow \mathrm{I}_{3}^{-}+2 \mathrm{e}^{-}$

This reaction provides two electrons that will be used to regenerate the dye. The electrolyte is then regenerated to the counter electrode. The use of electrolytes can present a major disadvantage due to improper cell sealing that causes evaporation, giving an unsuitable cell.

The counter-electrode regenerates the electrolyte, that is why it must have a low resistance to charge transfer and a high density of current exchange. Platinum is the most used material as a counter-electrode, but it is an extremely expensive element. A low cost alternative that deserves to be taken into consideration is carbon.

The photosensitive dye is a molecule that absorbs solar radiation, injecting an electron into the semi-conductor conduction band. Every sensitizer must have some particular characteristics: a) absorption in the visible range of light, b) chemisorption on the semi-conductor surface,c) efficient electronic injection into the semi-conductor conduction band, d) carboxyl or hydroxyl groups which can complex the titanium (Ti) on the surface of $\mathrm{TiO}_{2}$, e) a good ability to absorb photons.

Organic dyes, such as ruthenium complexes, or natural organic dyes, in particular flavonoids and anthocyanins, are the most common sensitizers used with this technology [3-6] but chlorophylls and carotenoids can also be used, provided some special precautions are taken [7]. Natural dyes are an excellent alternative to organic compounds. They have all of the basic features of a DSSC dye and, above all, are inexpensive and readily available. Chlorophyll (chl) is the main plant photosynthetic pigment. Photosynthetic organisms have different types of chlorophyll $\left(a, b, c_{1}, c_{2}, c_{3}\right.$ and d), but in higher plants only chl-a and chl-b are present [8]. Chl-a and chl-b differ in the molecular structure of a single side chain of the cyclic tetrapyrrole due to the presence of $\mathrm{CH}_{3}$ in chl-a and $\mathrm{CHO}$ in chl-b. These two molecules absorb light at different wavelengths; chl-a has two absorption peaks, the first one at $430 \mathrm{~nm}$ and the second one at $663 \mathrm{~nm}$; chl-b has absorption peaks at $480 \mathrm{~nm}$ and $650 \mathrm{~nm}$.

Chlorophylls can be considered ideal photosensitizers due to a highly stable polycyclic network of alternating single and double bonds (polyenes) conjugated structure, that allows the orbitals delocalization [3]. Nevertheless the presence of alkyl groups in the molecule hinders the efficient binding of these pigments on the nanoporous $\mathrm{TiO}_{2}$ surface [9]. Therefore, most of the literature reports in this field are concerning the use of pure or modified chl molecules $[7,10,11]$. Beside chl, carotenoids are terpenoid pigments that adsorb light for photosynthesis and protect the photosystems from photo-oxidation. They show an absorption peak near to 470 $\mathrm{nm}$. There are two classes of carotenoids: Carotenes (chemically formed by carbon and hydrogen) and Xanthophylls (chemically formed by carbon, hydrogen and oxygen).

Due to the expensive and sometimes strenuous procedures to obtain natural dye, the aim of this work was to verify the possibility of utilizing crude extracts of chlorophylls and carotenoids from crop species, in order to better use agricultural wastes. For this purpose we chose two important and widely used crops, e.g. spinach (Spinacia oleracea L.) and pepper (Capsicum annuum L.). The chl dye was extracted from leaves of spinach, while a xanthophyll dye was extracted from fruits of pepper. The latter are characterized by the presence of two xanthophylls (xanth), capsantin and capsorubin, that have hydroxyl groups (Figure 1), useful for the bindings on the $\mathrm{TiO}_{2}$ layer. 


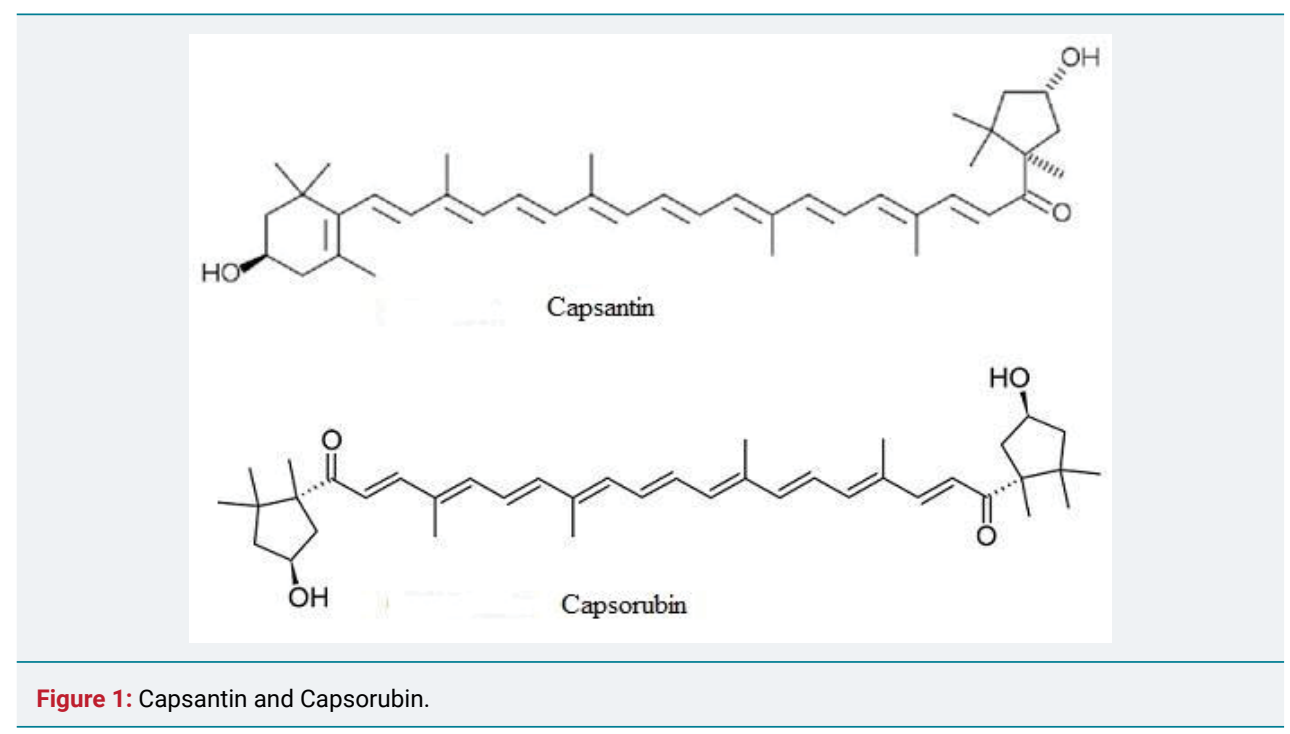

\section{Materials and Methods}

\section{Preparation of photo-anodes}

This preparation consists of different steps. A glass plate spattered with FTO is divided with a laser (Universal laser system ULS 30 Watt) in cells with three photoanodes; each photo-anode is separated from the others, so as to be electrically isolated. Every photo-anode was printed with a $0.25 \mathrm{~mm}^{2} \mathrm{TiO}_{2}$ nano-particle (diameter $20 \mathrm{~nm}$ ) layer, and then baked for 2 hours following a temperature ramp: 45 minutes from $100^{\circ} \mathrm{C}$ to $480^{\circ} \mathrm{C}, 30$ minutes at $480^{\circ} \mathrm{C}, 45$ minutes from $480^{\circ} \mathrm{C}$ to $100^{\circ} \mathrm{C}$. This process is called sintering and it turns $\mathrm{TiO}_{2}$ in a mesoporous material. A second $\mathrm{TiO}_{2}$ layer is printed above the previous one. This second layer is made with larger $\mathrm{TiO}_{2}$ particles (diameter $400 \mathrm{~nm}$ ) and then sintered again. The second layer is a scatter layer, and its purpose is to evenly spread the light on the bottom layer.

\section{Preparation of the basic solvent for chlorophyll extraction}

The solvent used during the chlorophyll extraction is a methanol-based solvent. A quantity of $\mathrm{NaOH}$ equal to $5 \%(\mathrm{w} / \mathrm{v})$ is added to methanol, and then stirred for 6 hours.

\section{Preparation of the dye: pigment extraction}

Chlorophylls (chl) were extracted from fresh or frozen leaves of spinach. 1.5 $\mathrm{g}$ (fresh weight) of leaves were homogenized in liquid nitrogen using a mortar and pestel. The powder obtained was suspended in $10 \mathrm{ml}$ of the basic solvent and then stirred at $5^{\circ} \mathrm{C}$ for 90 minutes. Then the samples were centrifuged 15 minutes at 1500 $\mathrm{x} \mathrm{g}$; the supernatants were collected and filtered $(0.2 \mu \mathrm{m}$ pore filters, Whatman $)$ and kept at $-20^{\circ} \mathrm{C}$ until use. Due to chlorophyll photo-sensitivity, all the steps of this protocol were performed under dim light and glassware containing dyes were covered with aluminium foil to minimize photooxidation. The performance of dyes obtained from fresh leaves were compared with those from frozen ones. Moreover, in order to determine the effect of preservation on dye stability, efficiency determinations were carried out with either one day old chlorophyll extracts or with extracts kept for one month at $-20^{\circ} \mathrm{C}$.

The xanthophyll (xanth) capsantin and capsorubin were extracted from fruits of red pepper ground according to the above described method. The xanth were extracted in methanol.

\section{Dye deposition on photo-anodes}

The photo-anodes were heated at $160^{\circ} \mathrm{C}$ for 10 minutes, in order to eliminate the 
residual humidity and then dipped into the dye sample and maintained at $4{ }^{\circ} \mathrm{C}$ for at least 4 hours. After that they were rinsed in ethanol for one minute and cleaned with moist paper to remove any solvent residues from the glass.

\section{Cell assembly}

The photo-anodes were fixed to the counter electrode with a layer of plastic material called Surlyn (SOLARONIX) and then pressed for $40 \mathrm{~s}$ at $100^{\circ} \mathrm{C}$. The particular shape of Surlyn allows the creation of three pockets on the layers of $\mathrm{TiO}_{2}$, in which the electrolyte is inserted using a vacuum pump. The cells were then sealed with a sealer (Threebond 3035 B UV resin) to prevent electrolyte evaporation. Finally, a silver paste is used to create cell contacts.

\section{Cell characterization}

The photo-electrochemical characterization of DSSC is carried out with a sunsimulator (ABET technologies Sun 2000 solar simulator) set at 1 sun light intensity. This characterization gives four output parameters:

- $\mathrm{V}_{\mathrm{oc}}$ : Open Circuit Voltage, measured in $\mathrm{mV}$.

- $\quad \mathrm{J}_{\mathrm{sc}}$ : Short Circuit Photocurrent. Measured in $\mathrm{mA} / \mathrm{cm}^{2}$.

- $\quad$ FF: Fill Factor, percentage value.

- $\quad \eta$ : efficiency, percentage value.

Every measurement of the DSSC was performed three times with 9 repetitions. The data are the average of the determinations \pm E.S.

\section{Results and Discussions}

Preliminary experiments performed using a crude chlorophyll extract were unsuccessful, since the lack of free carboxyl or hydroxyl groups did not allow the binding of the pigment on the $\mathrm{TiO}_{2}$ surface. Chl is characterized by the presence of two ester bonds that link two different substituents, one of them is the phytol group, on the porphyrin ring. The use of a basic solvent $(\mathrm{NaOH})$ allowed the basic hydrolysis of these two bonds, leaving two carboxyl groups on the porphyrin ring, allowing the binding on $\mathrm{TiO}_{2}$ surface (Figure 2).

The basic hydrolysis of chl induced changes in the absortion peaks (Figure 3).

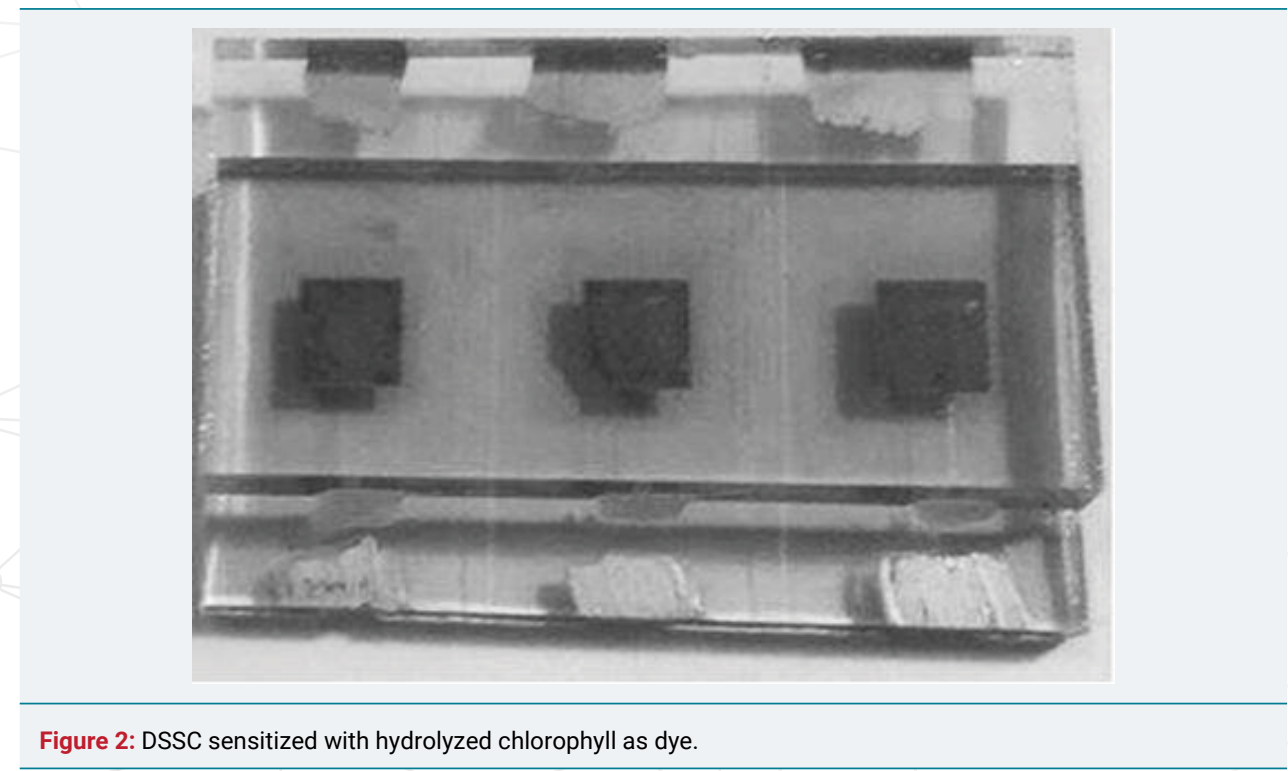


The principal bands of chl at 425.1 and $654.9 \mathrm{~nm}$ were shifted to 410 and $635 \mathrm{~nm}$ for hydrolizyzed chl.

The DSSC sensitized with the hydrolyzed chl showed high efficiency, Voc, Jsc and FF values (Table 1).

In order to detect the effect of preservation on the dye stability, efficiency determinations were carried out with 1 day or 1 month old dyes, maintained as described above. Table 1 shows the difference between old and newly extracted dyes. New dyes were more effective than the old ones, because of the degradation of the chl molecules in the samples. No differences between dyes derived from frozen or fresh leaves were detected (Table 1; Figure 4-7).

DSSC sensitized with xanth dyes showed different values compared to chl ones. Due to the hydroxyl groups of capsantin and capsorubin, the binding on the $\mathrm{TiO}_{2}$ layer surface always occurred, but these two xanthophylls were not effective as DSSC sensitizers. In Table 2 are reported the values obtained with DSSC sensitized with xanthophylls. Xanth. 1, Xanth. 2 and Xanth. 3 represent the three different extractions followed by three different sensitizations. The photo-electrochemical parameters were not significantly $(\mathrm{P}<0.001)$ different (Table 2). The values of xanth photo-electrochemical parameters were lower compared to chl DSSC.

The most used DSSC sensitizers are ruthenium compounds and anthocyanin dyes [5,6], since chlorophylls are not usually used as dyes because of the absence of carboxyl or hydroxyl groups preventing the binding to titania $[3,12]$. This absence requires the use of particular strategies, e.g. a different molecule can be used as a bridge between $\mathrm{TiO}_{2}$ and chlorophyll allowing the binding of the molecule on the $\mathrm{TiO}_{2}$ layer [3]. Usually these strategies are expensive and sometimes they

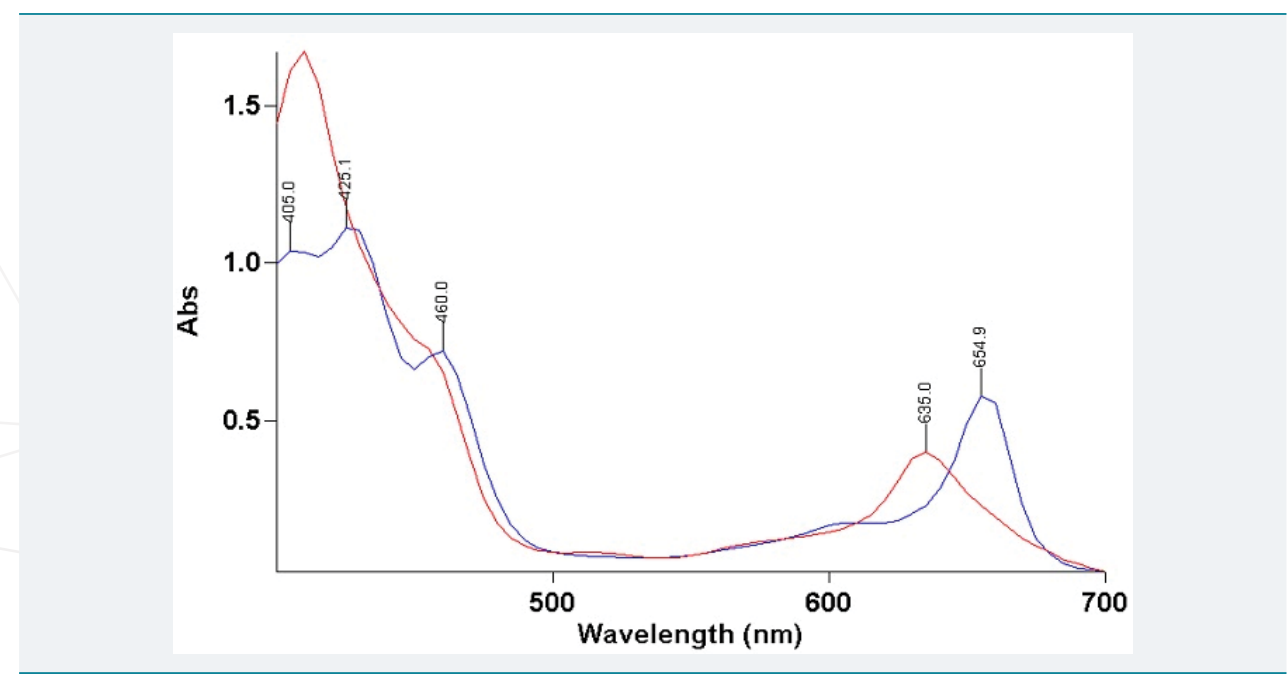

Figure 3: Absorption peaks from hydrolyzed chlorophyll (635.0 nm and $410.0 \mathrm{~nm}$, red line) and unhydrolyzed chlorophyll (654.9 $\mathrm{nm}$ and $425.1 \mathrm{~nm}$, blue line).

Table 1: $\mathrm{V}_{\mathrm{oc}^{\prime}} \mathrm{J}_{\mathrm{sc}^{\prime}}$ FF and $\eta$ of DSSC after three different sensitizations. The first sensitization was performed with 1 day old dye, extracted from frozen leaves (frz); the second sensitization was performed with 1 month old dye extracted by frozen leaves; the third sensitization was performed with a new dye ( 1 day) extracted by fresh (fr) leaves.

\begin{tabular}{|c|c|c|c|c|}
\hline & $\mathbf{V}_{\text {oc }} \mathbf{m V}$ & $\mathrm{J}_{\mathrm{sc}} \mathbf{m A} / \mathrm{cm}^{2}$ & FF \% & $\eta \%$ \\
\hline 1 day frz. leaf & $528.8 \pm 14.9$ & $-1.76 \pm 0.14$ & $57.05 \pm 2.7$ & $0.56 \pm 0.03$ \\
\hline 1 month frz. leaf & $627.77 \pm 7.22$ & $-0.75 \pm 0.05$ & $57.62 \pm 1.21$ & $0.28 \pm 0.02$ \\
\hline 1 day frz. leaf & $576.75 \pm 12$ & $-1.76 \pm 0.13$ & $61.06 \pm 0.7$ & $0.62 \pm 0.04$ \\
\hline
\end{tabular}




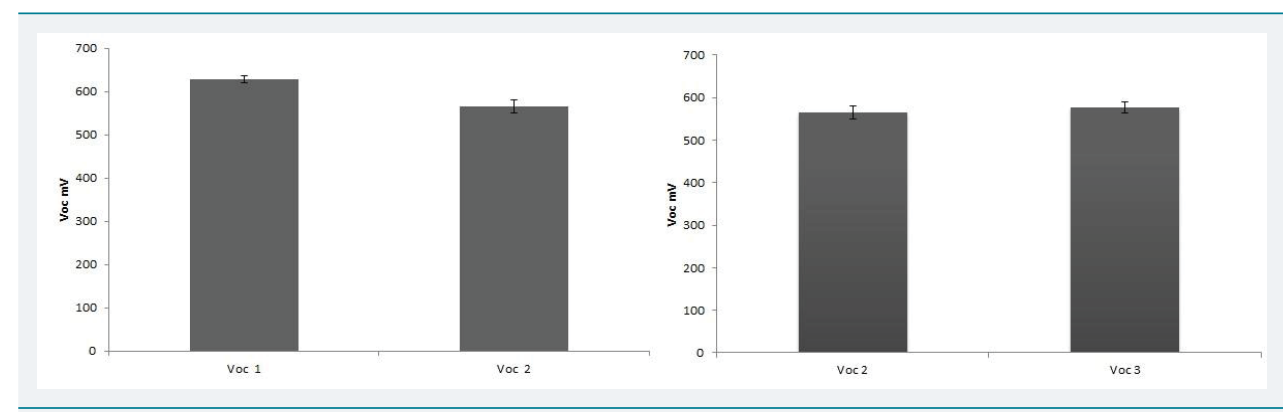

Figure 4: Comparison of Voc values between an old extract (Voc1, one month), and a fresh extract (Voc 2, one day). B) Comparison of Voc values between an extract from frozen leaves (Voc2) and an extract from fresh leaves (Voc3).

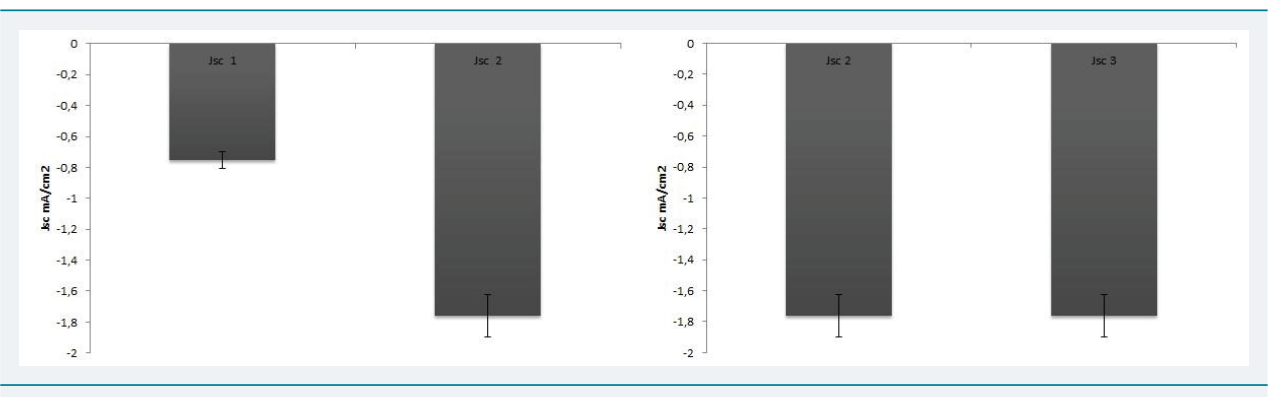

Figure 5: Comparison of Jsc values between an old extract (Jsc1 one month) and a fresh extract (Jsc2 one day). B) Comparison of Jsc values between an extract from frozen leaves (Jsc2) and an extract from fresh leaves (Jsc3).

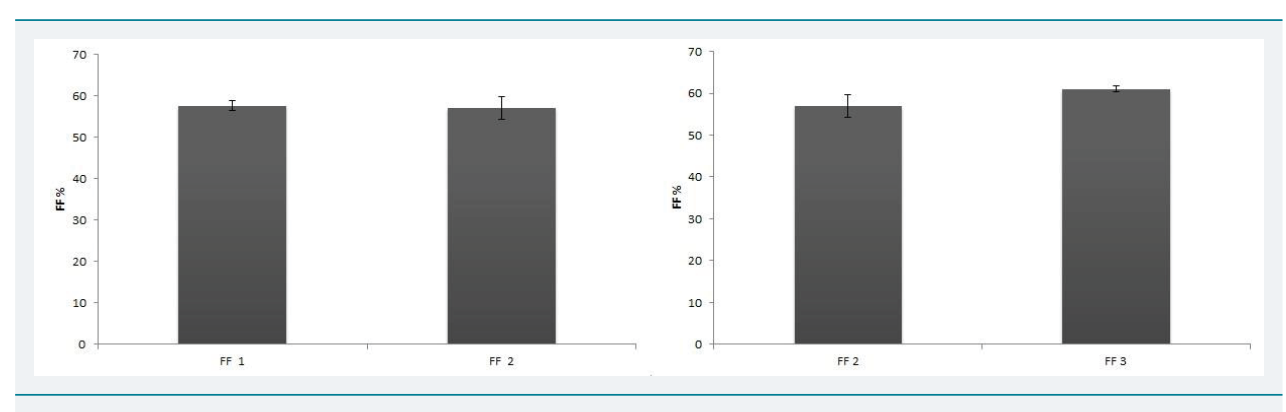

Figure 6: Comparison of FF values between an old extract (FF 1 one month), and a fresh extract (FF 2 one day) B) Comparison of FF values between an extract from frozen leaves (FF 2) and an extract from fresh leaves (FF 3).

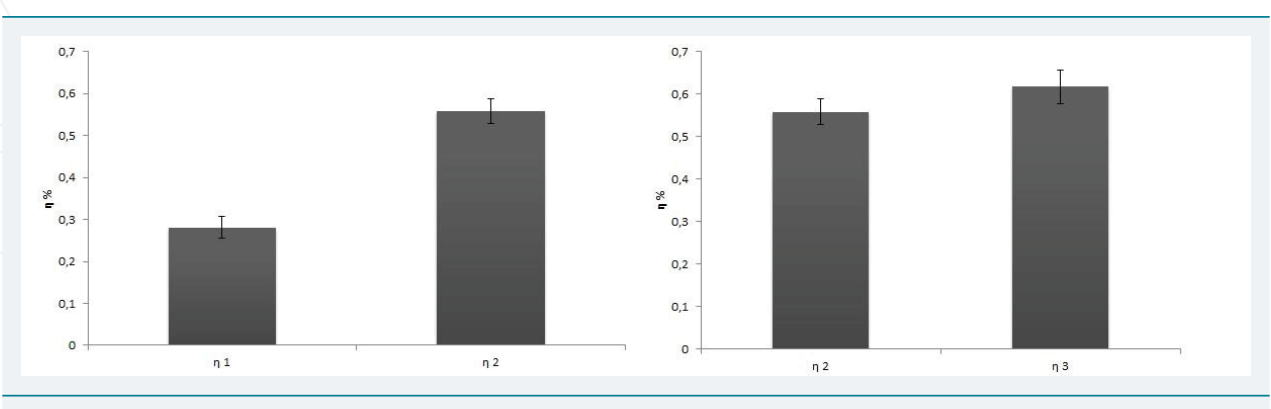

Figure 7: Comparison of $\eta$ values between an old extract ( $\eta 1$ one month), and a fresh extract ( $\eta 2$ one day). B) Comparison of $\eta$ values between an extract from frozen leaves $(\eta 2)$ and an extract from fresh leaves $(\eta 3)$.

can interfere with the light harvesting, resulting in a low DSSC efficiency. The extraction and the $\mathrm{NaOH}$ hydrolyzation procedure of chl described in this work is fast, economic and efficient; moreover due to the basic hydrolysis that provides free carboxylic groups, no different binding strategies are needed. This chl had a higher efficiency value $(0.62 \%$ average $\eta$ value) than the unhydrolyzed one obtained from spinach $(0.16 \%)$ and papaya leaves $(0.28 \%)[13,14]$ and one of the best of those reported in literature $(0.47 \%$ [2] and $0.46 \%$ [3] from spinach). The 
Table 2: Photo-electrochemical parameters values of DSSC sensitized with xanthophylls. The numbers 1,2 and 3 indicate the different extractions. The data are the average of 9 determinations $\pm \mathrm{ES}$ for each single extraction.

\begin{tabular}{|c|c|c|c|c|}
\hline & $\mathbf{V}_{\text {oc }} \mathbf{m V}$ & $\mathrm{J}_{\mathrm{sc}} \mathbf{m A} / \mathrm{cm}^{2}$ & $\mathbf{F F} \%$ & $\eta \%$ \\
\hline Xanth. 1 & $478.43 \pm 5.82$ & $-1.12 \pm 0.025$ & $52.9 \pm 0.57$ & $0.285 \pm 0.007$ \\
\hline Xanth. 2 & $390.16 \pm 2.74$ & $-1.29 \pm 0.022$ & $53.9 \pm 0.5$ & $0.272 \pm 0.226$ \\
\hline Xanth. 3 & $380.56 \pm 3.03$ & $-1.51 \pm 0.026$ & $54.5 \pm 0.54$ & $0.313 \pm 0.009$ \\
\hline
\end{tabular}

$\mathrm{NaOH}$ hydrolyzed chl shows higher efficiency compared to a KOH hydrolyzed chl $(0.002 \%)[15,16]$. If compared to synthetic dyes the bottle neck of chl- based DSSC is still the low efficiency; but if the performance/cost ratio is considered, this DSSC has a major advantage over both Ru-based and synthetic organic ones [3].

\section{Conclusions}

Our results confirm the literature reports about the potentiality of vegetable dyes as sensitizers in DSSCs. Chlorophyll is produced in large quantities from higher plants and it is highly available. From an economic point of view, the best choice may be to fabricate DSSCs with dye sensitizers, produced by simple hydrolysis of chlorophyll molecules extracted from crop plants. Capsantin and capsorubin could be good DSSC sensitizers because of their hydroxyl groups; the latter allow the binding to the $\mathrm{TiO}_{2}$ layer, but these xanthophylls are not high performance sensitizers in comparison to hydrolyzed chlorophyll. This opens new future perspectives about the use of agro-food industrial waste as low-cost sources of sensitizers for DSSC.

\section{Acknowledgements}

The authors are grateful to Prof. Bernard Glick for the critical review of the manuscript and to Dr. Daniele Cecchetti for the elaboration of the chemical structure of chlorophyll. This research did not receive any specific grant from funding agencies in the public, commercial, or not-for-profit sectors.

\section{References}

1. Grätzel M. Dye-sensitized solar cells. J. Photochem. Photobiol. C Photochem Rev. 2003; 4: 145153. Ref.: https://goo.gl/hEhbBh

2. Narayan MR. Dye sensitized solar cells based on natural photosensitizers. Ren Sustainable Energy Rev. 2012; 16: 208-215. Ref.: https://goo.gl/mHhZPg

3. Calogero G, Bartolotta A, Di Marco G, Di Carlo A, Bonaccorso F. Vegetable-based dye-sensitized solar cells. Chem Soc Rev. 2015; 44: 3244-3294. Ref.: https://goo.gl/UK1TK2

4. Calogero G, Sinopoli A, Citro I, Di Marco G, Petrov V, et al. Synthetic analogues of anthocyanins as sensitizers for dye-sensitized solar cells. Photochem Photobiol Sci. 2013; 12: 883-894. Ref.: https://goo.gl/8nXhVK

5. Teoli F, Lucioli S, Nota P, Frattarelli A, Matteocci F, et al. Role of pH and pigment concentration for natural dye-sensitized solar cells treated with anthocyanin extracts of common fruits. J. Photochem. Photobiol. A Chem. 2016; 316: 24-30. Ref.: https://goo.gl/FmFnUs

6. Di Bari C, Forni C, Di Carlo A, Barrajón-Catalan E, Micol V, et al. Pigments for natural dye sensitized solar cells from in vitro grown shoot cultures. J Photonics Energy. 2017; 7: 025503. Ref.: https://goo.gl/ueyJ8b

7. Amao Y, Kato K. Chlorophyll assembled electrode for photovoltaic conversion device. Sci. Direct. Electrochimica Acta. 2007; 53: 42-45. Ref.: https://goo.gl/UuS3pS

8. Ritchie RJ. Consistent sets of spectrophotometric chlorophyll equations for acetone, methanol and ethanol solvents. Photosynth Res. 2006; 89: 27-41. Ref.: https://goo.gl/At9jPn

9. Hao $\mathrm{S}, \mathrm{Wu} J$, Huang $\mathrm{Y}$, Lin J. Natural dyes as photosensitizers for dye-sensitized solar cells. Sol Energy. 2006; 80: 209-214. Ref.: https://goo.gl/QESYPi

10. Wang XF, Kitao O, Hosono E, Zhou H, Sasaki S, et al. $\mathrm{TiO}_{2}$ - and $\mathrm{ZnO}$-based solar cells using a 
chlorophyll a derivative sensitizer for light-harvesting and energy conversion. J Photochem Photobiol. A. 2010; 210: 145-152. Ref.: https://goo.gl/GssJCr

11. Wang XF, Tamiaki H, Wang L, Tamai N, Kitao O, et al. Chlorophyll-a derivatives with various hydrocarbon ester groups for efficient dye-sensitized solar cells: static and ultrafast evaluations on electron injection and charge collection processes. Langmuir. 2010; 26: 63206327. Ref.: https://goo.gl/TP1Fo7

12. Kay A, Grätzel M. Artificial Photosynthesis. 1. Photosensitization of $\mathrm{TiO}_{2}$ Solar Cells with Chlorophyll Derivatives and Related Natural Porphyrins. J Phys Chem. 1993; 97: 6272-6277. Ref.: https://goo.gl/jTtLL5

13. Chang $H$, Wu HM, Chen TL, Huang KD, Jwo CS, et al. Dye-sensitized solar cell using natural dyes extracted from spinach and ipomoea. J Alloys Compounds. 2008; 495: 606-610. Ref.: https://goo.gl/uEqNNf

14. Suyitno S, Saputra TJ, Supriyanto A, Arifin Z. Stability and efficiency of dye-sensitized solar cells based on papaya-leaf dye. Spectrochim. Acta A Mol Biomol Spectrosc. 2015; 148: 99104. Ref.: https://goo.gl/kuMcZW

15. Nagovitsyn IA, Chudinova GK, Komissarov GG. Effect of carotene on the photovoltaic and optical properties of Langmuir films of chlorophyll. Doklady Biochem Biophysics. 2001; 382: 1-3. Ref.: https://goo.gl/ANiWDN

16. Kartini I, Dwitasari L, Wahyuningsih T, Chotimah D, Wang L. Sensitization of xanthophyllschlorophyllin mixtures on titania solar cells. Internat. J Sci Eng. 2015; 8: 109-114. Ref.: https://goo.gl/DNPdyt 